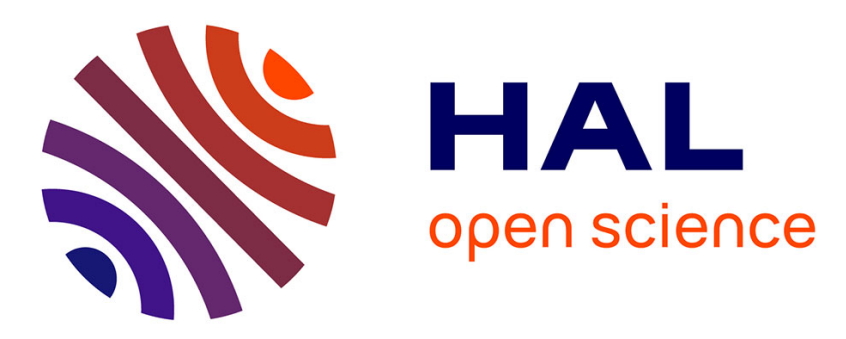

\title{
Markups and the Welfare Cost of Business Cycles: A Reappraisal
}

Jean-Olivier Hairault, François Langot

\section{To cite this version:}

Jean-Olivier Hairault, François Langot. Markups and the Welfare Cost of Business Cycles: A Reappraisal. Journal of Money, Credit and Banking, 2012, 44 (5), pp.995-1014. 10.1111/j.15384616.2012.00519.x . hal-00623281

\section{HAL Id: hal-00623281 \\ https://hal.science/hal-00623281}

Submitted on 13 Sep 2011

HAL is a multi-disciplinary open access archive for the deposit and dissemination of scientific research documents, whether they are published or not. The documents may come from teaching and research institutions in France or abroad, or from public or private research centers.
L'archive ouverte pluridisciplinaire HAL, est destinée au dépôt et à la diffusion de documents scientifiques de niveau recherche, publiés ou non, émanant des établissements d'enseignement et de recherche français ou étrangers, des laboratoires publics ou privés. 


\title{
Markups and the Welfare Cost of Business Cycles: A Reappraisal
}

\author{
Jean-Olivier Hairault * \\ Paris School of Economics (PSE) \& University Paris 1 \& IZA \\ joh@univ-paris1.fr \\ FRANÇOIS LANGOT \\ GAINS-TEPP (U. du Mans) \& Cepremap \& IZA \\ flangot@univ-lemans.fr
}

June 2011

\begin{abstract}
Gali et al. (2007) have recently shown quantitatively that fluctuations in the efficiency of resource allocation do not generate sizable welfare costs. In their economy, which is distorted by monopolistic competition in the steady state, we show that they underestimate the welfare cost of these fluctuations by ignoring the negative effect of aggregate volatility on average consumption and leisure. As monopolistic suppliers, both firms and workers aim to preserve their expected markups; the interaction between aggregate fluctuations and price-setting behavior results in average consumption and employment levels that are lower than their counterparts in the flexible-price economy. This level effect increases the efficiency cost of business cycles. It is all the more sizable with the degree of inefficiency in the steady state, lower labor-supply elasticities, and when prices instead of wages are rigid.
\end{abstract}

Keywords: Business cycle costs, inefficiency gap, New-Keynesian Macroeconomics JEL Codes: E32, E12

${ }^{*}$ We thank two anonymous referees for their particularly helpful remarks and suggestions. We are also indebted to Paul Beaudry, Jean-Pascal Bénassy, Florin Bilbiie and Franck Portier for helpful comments. Any errors and omissions are ours. 


\section{Introduction}

New-Keynesian Macroeconomics (Mankiw (1985), Ball and Romer (1989), Gali et al. (2007)) often claims that there are potentially large business-cycle costs due to the asymmetric welfare effect of expansions and recessions. There is indeed a fundamental asymmetry, provided that the monopolistic economy is not at the efficient allocation at the steady state: expansions are welfare-improving, as they bring the economy closer to the social optimum; recessions reduce welfare, as they push the economy further from the social optimum. A monopolistic economy with nominal rigidities produces fluctuations in the gap between the marginal product of labor and the household's consumption-leisure tradeoff, hereafter called gap fluctuations. The welfare costs of gap fluctuations can then be considered as the efficiency cost of business cycles. These movements in the efficiency of resource allocation should be separated from the variability induced by the business cycles, as they are particular to nominal rigidities and so can be stabilized, at least partially, by monetary policy. Are these fluctuations costly on average? In other words, is the efficiency loss in a recession greater than the efficiency gain from a symmetric expansion? Gali et al. (2007) show that aggregate fluctuations do generate some efficiency costs, although these are not quantitatively sizable. We here show that their evaluation underestimates the welfare costs of gap fluctuations by ignoring their impact on price- and wage-setting, which latter leads to greater efficiency gaps on average.

As Gali et al. (2007) aim to measure the efficiency costs of business cycles in a realistic economy, they consider a relatively highly-distorted steady state. However, once sizable distortions are introduced at the steady state (which are essential for the Keynesian argument of asymmetry between recessions and expansions) we can no longer neglect the effect of volatility on mean aggregates in welfare calculations (Sutherland (2002), Woodford (2003), Benigno and Woodford (2005), Schmitt-Grohé and Uribe (2007)and Gali (2008)). Perhaps surprisingly, Gali et al. (2007) leave this potential source of business cycle costs to one side. In this paper, we consider an economy with a distorted steady state due to monopolistic competition, i.e. with an efficiency gap even without any aggregate fluctuations, which we call the structural gap. On the other hand, the existence of nominal rigidities in conjunction with aggregate shocks implies gap fluctuations. Along the lines of Gali et al. (2007), our objective is to measure business-cycle costs of nominal rigidities relative to the flexible-price case: the efficiency costs of business cycles. As shown in Gali et al. (2007), gap fluctuations have a direct negative impact on welfare (the volatility effect). We add to this by showing that the risk associated with unexpected variations in markups affects price-setting behaviors, leading to an increase in the average level of the efficiency gap (the level effect).

We provide an explicit analysis of the relative importance of this level effect in a simplified one-period framework à la Ball and Romer (1987). This model is a useful baseline case, making the issues and results transparent. It allows us to isolate the basic interaction between nomi- 
nal rigidities and monopolistic competition in a stochastic environment, abstracting from any other types of imperfection, i.e. staggered nominal contracts and/or money-demand distortions. Relative to Ball and Romer (1987), we introduce risk aversion, imperfect competition in both the labor and product markets, and both technological and monetary shocks. In this theoretical framework, price- and wage-setting behavior, faced with aggregate uncertainty, increases average markups relative to the flexible-price case. As monopolistic suppliers aim to preserve their expected markups, prices and wages incorporate a "risk premium", in order to offset the negative correlation between markups and the level of production. This leads to an average efficiency gap that is above its structural value due to the existence of nominal rigidities in a stochastic monopolistic economy.

With passive money supply, we show that the level effect increases the welfare cost of gap fluctuations. This is all the more sizable as the steady state is highly distorted; and this holds all the more if the economy displays New-Keynesian features, i.e. a low labor-supply elasticity and price rigidity only for goods. Active monetary policy to restore the flexible-price allocation by stabilizing markups is then welfare-improving twofold: first by eliminating the fluctuations in the efficiency gap, and second by reducing average markups to their structural level.

The remainder of the paper is organized in four sections. Section 2 presents a canonical newKeynesian model with preset prices and wages. Section 3 derives the implications for the efficiency cost of fluctuations when the effect of aggregate volatility on the average allocation is taken into account. Section 4 presents the monetary-policy implications of the level effect. Section 5 then analyzes the consequences of the type of nominal rigidities for business-cycle costs, and the relative importance of the level and volatility effects. Last, Section 6 concludes.

\section{A canonical New-Keynesian framework}

We consider a one-period economy along the lines of Ball and Romer (1989) with both price and wage rigidities. We assume for simplicity that the economy consists of consumer-producer agents who sell a differentiated good produced using differentiated labor. This simple model is consistent with the reduced-form model proposed by Gali et al. (2007) and will allow us to easily derive our main results.

Preferences. We assume that the preferences of individual $j$ can be summarized by the following utility function:

$$
U\left(C_{j}, L_{j}\right)=\left(\frac{\nu}{\nu-1}\right) \frac{C_{j}^{1-\sigma}}{1-\sigma}-\left(\frac{\varepsilon-1}{\varepsilon}\right) \frac{N_{j}^{1+\phi}}{1+\phi}
$$

where $N_{j}$ is agent j's labor supply, $\sigma$ is the coefficient of relative risk-aversion $(\sigma>0)$ and $\phi$ measures the increasing marginal disutility of labor $(\phi>0)$. The coefficients on consumption 
and labor are chosen for computational convenience. The variable $C_{j}$ is an index of agent $j$ 's consumption:

$$
C_{j}=\left(\int_{0}^{1} C_{j, i}^{\frac{\varepsilon-1}{\varepsilon}} d i\right)^{\frac{\varepsilon}{\varepsilon-1}}
$$

where $\varepsilon$ is the elasticity of substitution between any two goods $(\varepsilon>1)$. The demand for any good $i$ is given by:

$$
C_{j, i}=\left(\frac{P_{i}}{P}\right)^{-\varepsilon} C_{j} \quad \forall i
$$

where $P_{i}$ and $P$ are the price of good $i$ and the general price index respectively. The budget constraint of agent $j$ who owns the firm producing good $i$ is then:

$$
P C_{j}=W_{j} N_{j}+\Pi_{i}
$$

with $\Pi_{i}$ being the profit from the production of good $i$ and $W_{j}$ the wage paid for skill $j$.

Technology. We assume that the production technology of good $i$ is linear with only labor input: $Y_{i}=A L_{i}$. There is a technological shock $A$ to production at each period with $E[A]=1$. As goods are imperfect substitutes, competition between firms is monopolistic. The profit from the production of good $i$ is:

$$
\Pi_{i}=P_{i} Y_{i}-W L_{i}
$$

with $W$ being the general wage index. The labor used to produce each good is a CES aggregate of the continuum of individual labor types:

$$
L_{i}=\left(\int_{0}^{1} L_{i, j}^{\frac{\nu-1}{\nu}} d j\right)^{\frac{\nu}{\nu-1}}
$$

The parameter $\nu$ reflects the elasticity of substitution between any two skills $(\nu>1)$. As skills are imperfect substitutes, the competition between individuals is also monopolistic. The demand for any skill $j$ is thus:

$$
L_{i, j}=\left(\frac{W_{j}}{W}\right)^{-\nu} L_{i} \quad \forall j
$$

Money. We assume that money is required for transactions: $C=M / P$. For the moment, money supply is assumed to be stochastic and exogenous, with $E[M]=1$.

Pre-set prices and wages. Prices and wages are set before money supply and technology are revealed. Consider individual $j$ who sets both the price of good $i$ and the wages of labor type $j$. She is faced with her budget constraint, the general price index $P$, the aggregate wage index $W$, the goods demand function $C_{i}=\left(\frac{P_{i}}{P}\right)^{-\varepsilon} C$ and the labor demand function $L_{j}=\left(\frac{W_{j}}{W}\right)^{-\nu} L$. 
Optimal pre-set prices and wages result from the following program:

$$
\max _{P_{i}, W_{j}} E\left[\left(\frac{\nu}{\nu-1}\right) \frac{\left[\frac{W}{P}\left(\frac{W_{j}}{W}\right)^{1-\nu} L+\frac{\Pi_{i}}{P}\right]^{1-\sigma}}{1-\sigma}-\left(\frac{\varepsilon-1}{\varepsilon}\right) \frac{\left[\left(\frac{W_{j}}{W}\right)^{-\nu} L\right]^{1+\phi}}{1+\phi}\right]
$$

with $\Pi_{i}=\left(P_{i}-\frac{W}{A}\right)\left(\frac{P_{i}}{P}\right)^{-\varepsilon} C$. The optimal price satisfies the following first-order condition:

$$
E\left[U_{1}\left(C_{j}\right) Y_{i}\left(P_{i}-\frac{\varepsilon}{\varepsilon-1} \frac{W}{A}\right)\right]=0
$$

where $U_{1}$ is the partial derivative of utility with respect to consumption. The first-order condition for the optimal wage is:

$$
E\left[U_{1}\left(C_{j}\right) N_{j}\left(\frac{W_{j}}{P}-\frac{\nu}{\nu-1} \times M R S_{j}\right)\right]=0
$$

where $M R S$ denotes the marginal rate of substitution between consumption and leisure.

The risk premium on prices and wages. Assuming a symmetric equilibrium in prices $\left(P_{i}=P_{0}, \forall i\right)$ and wages $\left(W_{j}=W_{0}, \forall j\right)$, the first-order condition for the pre-set price $P_{0}$ (equation (1)) can be written as:

$$
E[\underbrace{U_{1}(C) Y}_{\text {scale }} \underbrace{\left[P_{0}-\frac{\varepsilon}{\varepsilon-1} \frac{W_{0}}{A}\right]}_{\text {price markup }}]=0
$$

As we have $C=M / P_{0}=Y$ in general equilibrium, equation (3) can be rewritten as follows:

$$
E[\underbrace{\left(\frac{M}{P_{0}}\right)^{1-\sigma}}_{\text {scale }} \underbrace{\left[P_{0}-\frac{\varepsilon}{\varepsilon-1} \frac{W_{0}}{A}\right]}_{\text {price markup }}]=0
$$

If the scale of the production is negatively correlated with the price markup, the price will be set above its deterministic level in order to compensate for the presence of unexpected shocks once prices have been set. This negative correlation exacerbates the risk that the firm's price markup be below its optimal value, and the pre-set price over the deterministic level acts like a risk premium to compensate for aggregate volatility. The premium reduces the probability of being in the bad state for monopolistic good suppliers, i.e. selling more when markups are too low. This risk premium can in turn affect the mean aggregates in the stochastic economy. It should be noted that if $A$ and $M$ are independent, there is no price risk premium when both wages and 
prices are rigid. ${ }^{1}$ Assuming that either monetary policy reacts to technological shocks or wages are flexible will introduce a correlation between the shocks and the aggregates in price-setting.

At the symmetric equilibrium, the first-order condition for the pre-set wage $W_{0}$ (equation (2)) becomes:

$$
E[\underbrace{U_{1}(C) N}_{\text {scale }} \underbrace{\left[\frac{W_{0}}{P_{0}}-\frac{\nu}{\nu-1} \times M R S\right]}_{\text {wage markup }}]=0
$$

and, as $C=\frac{M}{P_{0}}=Y=A N$,

$$
E[\underbrace{\left(\frac{M}{P_{0}}\right)^{1-\sigma}\left(\frac{1}{A}\right)}_{\text {scale }} \underbrace{\left[\left(\frac{W_{0}}{P_{0}}\right)-\frac{\varepsilon-1}{\varepsilon}\left(\frac{M}{P_{0}}\right)^{\phi+\sigma} A^{-\phi}\right]}_{\text {wage markup }}]=0
$$

Both monetary and technological shocks can yield covariance between the wage markup and the units of labor valued by the marginal utility of consumption (the scale of exchange on the labor market). A negative correlation implies that households pre-set their wage above the deterministic level. This risk premium allows households to reduce the probability of having to work more when the wage markup is below its desired level. This bad state pertains when a negative productivity shock induces an increase in both labor and the marginal rate of substitution. The more volatile are productivity shocks, the higher the pre-set wage, which in turn pushes up the pre-set price. $^{2}$ However, monetary shocks have more ambiguous effects: a monetary shock implies positive covariance between the scale of exchange and the wage markup when the change in the marginal utility of consumption dominates the movement in hours of work.

The efficiency gap in equilibrium. We define the efficiency gap as in Gali et al. (2007) as:

$$
G A P=\frac{M R S}{M P N}=\frac{\frac{U_{2}(N)}{U_{1}(C)}}{A}=\frac{U_{2}(N) N}{U_{1}(C) C}
$$

where $G A P \in[0 ; 1]$. With no aggregate fluctuations or in a flexible-price economy, the efficiency gap is constant and equals $\left(\frac{\varepsilon-1}{\varepsilon}\right)\left(\frac{\nu-1}{\nu}\right) \equiv 1-\Phi$, where $\Phi$ is a measure of structural inefficiency due to monopolistic competition on both the labor and goods markets.

\footnotetext{
${ }^{1}$ In the assumed linear production function, the marginal product of labor is exogenous and depends only on $A$. This removes another source of volatility in the price markup due to monetary shocks. This simplification is then a conservative choice.

${ }^{2}$ Note that mean consumption may be affected even if consumption does not fluctuate over the business cycle. When there are only productivity shocks, consumption does not fluctuate as real balances are constant. However, average consumption will be affected via agents' price- and wage-setting conditions (1) and (2).
} 
When prices and wages are rigid, the efficiency gap varies with aggregate shocks. The preset prices and wages interact to determine the equilibrium risk premia on wages and prices. Equations (3) and (5) can be respectively expressed as follows:

$$
\begin{aligned}
\frac{W_{0}}{P_{0}} E\left[U_{1}(C) \frac{Y}{A}\right] & =\frac{\varepsilon-1}{\varepsilon} E\left[U_{1}(C) Y\right] \\
\frac{W_{0}}{P_{0}} E\left[U_{1}(C) \frac{Y}{A}\right] & =\frac{\nu}{\nu-1} E\left[U_{1}(C) \frac{Y}{A} M R S\right]
\end{aligned}
$$

So we have:

$$
E\left[U_{1}(C) Y((1-\Phi)-G A P)\right]=0
$$

Aggregate shocks yield fluctuations in the efficiency gap around its structural level. Equation (10) includes the interactions between aggregate consumption and labor on the one hand, and price and wage markups on the other hand, reflected in equations (3) and (5). In the general equilibrium, equation (10) can be rewritten as:

$$
E\left[\left(\frac{M}{P_{0}}\right)^{1-\sigma}-\left(\frac{M}{P_{0}}\right)^{1+\phi} A^{-(1+\phi)}\right]=0
$$

The interaction between aggregate movements in the efficiency gap and price- and wage-setting behavior results in average consumption and employment levels that differ from their flexibleprice counterparts. This is a potential source of business-cycle costs. This level effect is particular to the economy with nominal rigidities, as it arises from the interaction between the shocks and price- and wage-setting.

\section{The efficiency costs of business cycles}

When there are nominal rigidities, the efficiency gap will vary over time. In the following, we derive the additional welfare costs of these business-cycle fluctuations due to nominal rigidities (relative to flexible prices): these are the efficiency costs of business cycles. Along the lines of Gali et al. (2007), movements in the efficiency gap have a direct negative impact on welfare (the volatility effect). More originally, we here show that uncertainty over the markups affects priceand wage-setting, leading to a greater average efficiency gap (the level effect).

A welfare-based measurement. As in Gali et al. (2007), consider a second-order approximation to welfare around the flexible-price economy path (the upper bar variables):

$U(C, N) \approx U(\bar{C}, \bar{N})+U_{1}(\bar{C}) \bar{C}\left(\widetilde{C}+\frac{1}{2} \widetilde{C}^{2}\right)-U_{2}(\bar{N}) \bar{N}\left(\widetilde{N}+\frac{1}{2} \widetilde{N}^{2}\right)+\frac{1}{2} U_{11}(\bar{C}) \bar{C}^{2} \widetilde{C}^{2}-\frac{1}{2} U_{22}(\bar{N}) \bar{N}^{2} \widetilde{N}^{2}$ 
where the tilde denotes the $\log$ deviation from the flexible-price economy. ${ }^{3}$ Given the utility function, the approximate welfare gap between the rigid- and flexible-price economies is:

$$
\Delta \equiv U(C, N)-U(\bar{C}, \bar{N}) \approx U_{1}(\bar{C}) \bar{C}\left(\widetilde{C}+\frac{1-\sigma}{2} \widetilde{C}^{2}\right)-U_{2}(\bar{N}) \bar{N}\left(\widetilde{N}+\frac{1+\phi}{2} \widetilde{N}^{2}\right)
$$

The efficiency cost of business cycles, traditionally expressed in terms of consumption, is then:

$$
\frac{\Delta}{U_{1}(\bar{C}) \bar{C}} \approx\left(\widetilde{C}+\frac{1-\sigma}{2} \widetilde{C}^{2}\right)-(1-\Phi)\left(\widetilde{N}+\frac{1+\phi}{2} \widetilde{N}^{2}\right)
$$

As $\widetilde{C}=\widetilde{N}$, we have:

$$
\frac{\Delta}{U_{1}(\bar{C}) \bar{C}} \approx \Phi \widetilde{C}_{t}-\frac{1}{2}[(\phi+\sigma)-\Phi(1+\phi)] \widetilde{C}_{t}^{2}
$$

We then express the average efficiency cost as follows:

$$
E\left(\frac{\Delta}{U_{1}(\bar{C}) \bar{C}}\right) \approx \underbrace{\Phi E(\widetilde{C})}_{\text {Level Effect }}-\underbrace{\frac{1}{2}[(1-\sigma)-(1-\Phi)(1+\phi)] \operatorname{var}(\widetilde{C})}_{\text {Volatility Effect }}
$$

The efficiency costs of business cycles are measured by the gap between consumption and its natural level. ${ }^{4}$ These can be broken down into two terms. Firstly, there is a cost from movements in the consumption gap (the volatility effect); second, average consumption in the fluctuating economy may be lower than in the flexible-price counterpart (the level effect).

The consumption gap $\widetilde{C}$. Equilibrium consumption is demand-driven in the fixed-price economy and technology-driven in the flexible-price economy:

$$
\begin{aligned}
& C=\frac{M}{P_{0}} \\
& \bar{C}=A^{\frac{1+\phi}{\sigma+\phi}}
\end{aligned}
$$

We can then deduce that:

$$
\widetilde{C}=\log \left(\frac{M}{P_{0}}\right)-\frac{1+\phi}{\sigma+\phi} \log (A)
$$

A second-order approximation of the above equation around the deterministic economy ${ }^{5}$ leads to:

$$
\widetilde{C} \approx(M-1)-\frac{1}{2}(M-1)^{2}+\left(\frac{1}{P_{0}}-1\right)-\frac{1}{2}\left(\frac{1}{P_{0}}-1\right)^{2}-\frac{1+\phi}{\sigma+\phi}\left[(A-1)-\frac{1}{2}(A-1)^{2}\right]
$$

Only $P_{0}$ is endogenous in this expression for $\widetilde{C}$.

\footnotetext{
${ }^{3} \tilde{X}=\log (X / \bar{X}), X=C, N$.

${ }^{4}$ Note that the consumption gap is equal to the output gap, the gap between output and its natural level.

${ }^{5}$ We consider that money supply and technology are set to 1 in the deterministic model. In this case, it is straightforward to show that the price equals 1.
} 
The determination of the pre-set price $P_{0}$. Taking a second-order approximation of equation (11) around the deterministic economy yields:

$$
\begin{aligned}
0 \approx & -(\sigma+\phi)\left(\frac{1}{P_{0}}-1\right)-\frac{(1-\sigma) \sigma+(1+\phi) \phi}{2}\left(\frac{1}{P_{0}}-1\right)^{2} \\
& -\frac{(1-\sigma) \sigma+(1+\phi) \phi}{2} \operatorname{var}(M)-\frac{(1+\phi)(2+\phi)}{2} \operatorname{var}(A)
\end{aligned}
$$

Implicit differentiation then yields:

$$
\frac{1}{P_{0}} \approx 1-\frac{1}{2}(1+\phi-\sigma) \operatorname{var}(M)-\frac{1}{2} \frac{(1+\phi)(2+\phi)}{\sigma+\phi} \operatorname{var}(A)
$$

This expression is a generalization ${ }^{6}$ of the result in Ball and Romer (1989). As prices are equal to 1 in the deterministic economy, equation (14) clearly reveals that pre-set prices in the stochastic economy may be higher than those in the deterministic economy. As explained for equations (3) and (5), the volatility of the productivity shocks has an unambiguously positive effect on pre-set prices. On the other hand, the impact of the variance of monetary shocks is ambiguous: this increases prices if $\sigma<1+\phi$.

Volatility Effect. We first examine the efficiency cost due to the volatility effect as defined in equation (12). This is the cost that Gali et al. (2007) consider. ${ }^{7}$ Combining equations (12), $(13)$ and (14), and neglecting terms of order greater than 2, we derive the volatility effect $(V E)$ in the efficiency cost as follows:

$$
V E=-\frac{1}{2}[(\phi+\sigma)-\Phi(1+\phi)] \underbrace{\left(\operatorname{var}(M)+\left(\frac{1+\phi}{\sigma+\phi}\right)^{2} \operatorname{var}(A)\right)}_{V(\tilde{C})}
$$

First, for a given volatility of the consumption gap, equation (12) shows that the greater are $\sigma$ and $\phi$, the higher is the volatility effect in the efficiency cost of business cycles. Efficiency gains in expansions are dominated by the efficiency losses in recessions due to the concavity of individual preferences: gap fluctuations are thus asymmetric between expansions and recessions. On the other hand, equation (15) shows that the volatility of the consumption gap for a given volatility of monetary and technological shocks falls with $\sigma$ but rises with $\phi$, provided that $\sigma>1$. Overall, the volatility effect rises with $\sigma$ and $\phi$. Moreover, equation (12) explains why

\footnotetext{
${ }^{6}$ Note that in Ball and Romer (1989), we have $\sigma=0, \gamma=1+\phi, \operatorname{var}(A)=0$ and no wage rigidity. See Section 5 for a case that is closer to Ball and Romer (1989).

${ }^{7}$ Note that it is possible to derive the volatility effect in terms of the volatility of the efficiency gap, as in Gali et al. (2007). Taking the relative deviation of the efficiency gap from its deterministic path $\left(\widehat{G A P}=\frac{G A P-\overline{G A P}}{\overline{G A P}}\right)$, we can show, taking a second-order approximation of equation (7) around the deterministic state, that: $V E=$ $-\frac{1}{2} \frac{1}{\sigma+\phi}\left(1-\frac{\Phi(1+\phi)}{\sigma+\phi}\right) \operatorname{var}(\widehat{G A P})$. This reduced form can be useful to measure the efficiency costs of business cycles based on the observed volatilities of consumption and labor. However, it obscures the influence of the structural parameters $\phi$ and $\sigma$ on the volatility of the efficiency gap for a given volatility of shocks.
} 
the volatility effect falls with the structural gap $(\Phi)$ : labor volatility is less costly in terms of consumption in an economy with a lower marginal rate of substitution between consumption and leisure.

The level effect. We now turn to the level effect in the efficiency costs of business cycles (equation (12)). There is a fall in average consumption relative to the flexible-price economy, due to the interaction between fluctuations and nominal rigidities: the consumption gap is negative on average. Combining equations (12), (13) and (14), and neglecting terms of order greater than 2 , the level effect $(L E)$ can be written as:

$$
L E=\Phi E[\widetilde{C}] \approx-\frac{\Phi}{2}\left[(2+\phi-\sigma) \operatorname{var}(M)+\frac{(1+\phi)^{2}}{\sigma+\phi} \operatorname{var}(A)\right]
$$

The level effect has a stronger negative effect on welfare as the structural efficiency gap $\Phi$ is larger, i.e. as the marginal rate of substitution between consumption and leisure is lower. A negative consumption gap increases efficiency costs more when steady-state consumption is lower. With pre-set wages as explained above, monetary shocks have an ambiguous impact on the level effect. On the other hand, both price- and wage-setting rules unambiguously generate a negative level effect in the presence of technological shocks. Overall, the higher is $\sigma(\phi)$, the smaller (larger) the level effect (in absolute terms).

The relative contribution of the level effect. We denote by $\gamma$ the ratio of the level to the volatility effect: $\gamma=\frac{L E}{V E}$. This ratio rises with $\Phi$ as this latter increases the level effect but reduces the volatility effect. It is worth emphasizing that an increase in the structural gap now has an indeterminate effect on business-cycle costs. Without taking the level effect into account, this effect would be negative and the welfare cost of the gap fluctuations would be maximized at $\Phi=0$. Including the level effect, a more highly-distorted economy at the steady state may increase business-cycle costs:

$$
\frac{\partial E\left(\frac{\Delta}{U_{1}(\bar{C}) \bar{C}}\right)}{\partial \Phi}=-\frac{1}{2}\left(\operatorname{Var}(A) \frac{(1+\phi)^{2}}{(\sigma+\phi)^{2}}-\operatorname{Var}(M)\right)(\sigma-1)
$$

If the volatility of productivity shocks is sufficiently large relative to that of monetary shocks, provided that $\sigma>1$, the more distorted is the steady state, the greater the efficiency costs of business cycles. The structural level of the efficiency gap and nominal rigidities may then interact to magnify business-cycle costs.

On the other hand, the level effect may easily dominate the volatility effect, i.e. $\gamma>1$. Note that for $\sigma$ close to $1, \gamma \approx \Phi /(1-\Phi)$. In the benchmark calibration proposed by Gali et al. (2007) with $\Phi=0.5$, the level and volatility effects make the same contribution to business-cycle costs. For $\Phi=0.65$, which is still a realistic value, $\gamma$ is almost equal to 2 . 
Furthermore, the relative contribution of the level effect $(\gamma)$ falls with $\sigma$, as the latter increases the volatility effect but reduces the level effect. In contrast, the effect of the marginal disutility of labor $\phi$ is not a priori determined, as greater $\phi$ amplifies both the level and volatility effects. We resort to numerical simulations of equations (15) and (16) to measure this (Table 1). ${ }^{8}$ In this sensitivity analysis, the variance of the two shocks has to be calibrated, as the parameter effects depend on these variances. To be comparable with Gali et al. (2007), and to only focus on differences due to the level effect, we calibrate these variances to be consistent with the business cycle costs in Gali et al. (2007) when only volatility effects matter. We use two targets taken from Table 4 in Gali et al. (2007): ${ }^{9}$ the volatility effect $V E$ equals 0.01 for $\sigma=1$ and $\phi=1$, and 0.027 for $\sigma=5$ and $\phi=1$. The two standard deviations are calibrated at the same value of $1 \%$. We last have to calibrate $\sigma$ : in the sensitivity analysis for the $\phi$ and $\Phi$ parameters in Table 1 , we set $\sigma$ to the consensual value of 1.5 (see for instance Attanasio et al. (1999)).

In Table 1, it is worth emphasizing that lower values of the labor-supply elasticity (higher values of $\phi$ ) increase both the contribution of the level effect and the efficiency costs of business cycles. Whereas the relative contribution of the level effect and business-cycle costs equal 0.63 and $0.02 \%$ respectively for $\phi=1$, these become 0.91 and $0.11 \%$ for $\phi=10$ when considering $\Phi=0.5$. The value of $\Phi$ significantly affects the relative importance of the level effect, but not business-cycle costs, as $\sigma$ is close to 1 and the structural shock volatilities are the same. In a typical Keynesian economy, with a small elasticity of labor supply and considerable structural inefficiency, the level effect dominates and business-cycle costs are quite sizable. ${ }^{10}$ When $\Phi$ reaches 0.70 , the level effect accounts for two-thirds of the $0.11 \%$ permanent consumption loss.

\section{A monetary policy rule}

In this section, we first determine the impact of a given monetary rule on the level and volatility effects. As in any pre-set price model in the tradition of Phelps and Taylor (1977) and Fischer (1977), we then derive monetary policy contingent on aggregate shocks that eliminate consumption gap volatility, and thus the drop in average consumption. As already noted by Benigno and Woodford (2005), restoring the flexible-price allocation is optimal even in a distorted steady state.

\footnotetext{
${ }^{8}$ Instead of the numerical analysis of approximated functions, we could carry out stochastic simulations of the decision rules in order to use the exact values of consumption and leisure. We check that the two approaches yield very similar numbers. Our approximation of the welfare function up to the second order is therefore a good one, and hence the effect of the mean on volatility can be neglected.

${ }^{9}$ We check that these variances allow us to replicate the order of magnitude of all of the results in Table 4 in Gali et al. (2007).

${ }^{10}$ It might be thought that this is still small but our objective here is more methodological than quantitative. The impact of the level effect on the size of business-cycle costs in a more empirically-relevant framework is left for further research.
} 
Table 1: Sensitivity Analysis (Rigid prices-Rigid wages)

\begin{tabular}{|c|c|c|c|c|c|c|}
\hline & \multicolumn{2}{|c|}{$\phi=1$} & \multicolumn{2}{|c|}{$\phi=5$} & \multicolumn{2}{|c|}{$\phi=10$} \\
\hline & $\gamma$ & Welf. cost & $\gamma$ & Welf. cost & $\gamma$ & Welf. cost \\
\hline$\Phi=0.5$ & $0.63^{a}$ & 0.0201 & 0.85 & 0.060 & 0.91 & 0.11 \\
\hline$\Phi=0.6$ & 0.87 & 0.0200 & 1.23 & $0.060^{b}$ & 1.34 & 0.11 \\
\hline$\Phi=0.7$ & 1.20 & 0.0199 & 1.81 & 0.059 & 2.02 & 0.11 \\
\hline \multicolumn{7}{|c|}{$\begin{array}{l}a \text { : The level effect amounts to } 63 \% \text { of the volatility effect when } \\
\text { the structural efficiency gap } \Phi \text { equals } 0.5 \text { and the marginal } \\
\text { disutility of labor } \phi \text { equals } 1 .\end{array}$} \\
\hline
\end{tabular}

An active money-supply rule and the efficiency cost of business cycles. We assume that the Central Bank commits to implementing the following state-contingent rule:

$$
M=\bar{M} A^{\pi}
$$

For comparison to the case with exogenous monetary shocks, we consider that $\bar{M}=1$. In order to derive the implications of active monetary policy, using equations (11) and (18), and taking a second-order approximation around the deterministic path, it is possible to show that:

$$
\frac{1}{P_{0}}=1-\frac{1}{2} \frac{\Xi}{\sigma+\phi} \operatorname{var}(A)
$$

where $\Xi=-\pi(1-\sigma)[\pi(1-\sigma)-1]+(1+\phi)(\pi-1)[(1+\phi)(\pi-1)-1]$

From equation (13), using equations (18) and (19), it is then straightforward to derive the expressions for the level and volatility effects:

$$
L E=\Phi E[\widetilde{C}]=-\frac{\Phi}{2} \frac{\Xi+\pi(\sigma+\phi)-(1+\phi)}{\sigma+\phi} \operatorname{var}(A)
$$

and

$$
V E=-\frac{1}{2}[(\phi+\sigma)-\Phi(1+\phi)] \underbrace{\left[\pi-\frac{1+\phi}{\sigma+\phi}\right]^{2} \operatorname{var}(A)}_{\operatorname{var}(\widetilde{C})}
$$

The way in which monetary policy reacts to technological shocks modifies both the volatility and the level effects. The volatility effect can obviously be attenuated by this policy: if money supply rises with technological shocks $(\pi>0)$, aggregate consumption will become closer to its flexible-price economy counterpart, gap fluctuations are stabilized and the volatility effect dampened. Will this pro-cyclical monetary-policy rule also reduce the level effect? As explained above, with a passive rule, the uncertainty over the technological shocks implies that wages and prices are pre-set above their deterministic values. A negative productivity shock, before any money-supply reaction, increases labor, the marginal cost and the marginal rate of substitution 
between consumption and leisure, implying that prices will be pre-set above their deterministic value. Were money supply to fall as in a pro-cyclical monetary-policy rule, both labor and the marginal rate of substitution would fall as money supply contracts. An active monetary policy regarding productivity shocks can modify the risks associated with wage and price markups and so change the level effect. The pre-set price will fall, as does the impact of the level effect on business-cycle costs.

Replicating the flexible-price allocation. There exists one particular monetary rule under which the monopolistic economy with nominal rigidities replicates its flexible-price counterpart. This implies eliminating the gap fluctuations. With a monetary-policy rule parameter of $\pi=$ $\frac{1+\phi}{\sigma+\phi}$, the volatility effect obviously vanishes, as expected: $\operatorname{var}(\widetilde{C})=0$. But the level effect vanishes too: $E[\widetilde{C}]=0$ for $\pi=\frac{1+\phi}{\sigma+\phi}$. We can check from equation (19) that the price is pre-set at 1 , its deterministic value, under this monetary-policy rule. Monetary policy stands in for real wage adjustments in setting the efficiency gap constant at its structural level $1-\Phi$. If the private sector expects that the Central Bank will react to eliminate gap fluctuations, it is optimal from an individual perspective to pre-set prices at the same level as in an economy without markup fluctuations. ${ }^{11}$ This ensures that both the level and volatility effects disappear under the monetary policy rule $\pi=\frac{1+\phi}{\sigma+\phi}$. In Appendix A, it is shown, adopting a Ramsey approach, that the monetary rule aiming at replicating the flexible-price allocation is optimal, whatever the level of the steady-state distortion. This provides a simple illustration of the result in Benigno and Woodford (2005) which they obtain using a more complex set-up. This monetary-policy rule then likely generates greater welfare gains than shown traditionally in a non-distorted steady-state framework.

\section{Sensitivity to the type of nominal rigidity}

In the previous sections, both prices and wages were rigid. In order to identify the role of each type of rigidity, this section considers models with only sticky prices and only sticky wages.

Rigid prices and flexible wages. In the case with only sticky prices, the wage rule (equation 5) is modified as follows:

$$
W=\frac{\nu}{\nu-1} P_{0} \times M R S
$$

whereas the pre-set price rule (equation (3)) is unchanged, except that the wage is now given by equation (20), and no longer pre-set at $W_{0}$. This yields another source of volatility for the price markup. It results straightforwardly that replacing the wage in equation (3) by equation

\footnotetext{
${ }^{11}$ Note that the pre-set wage differs from its deterministic level, but that this does not affect the real resource allocation when prices are rigid.
} 
(20) still leads to equation (10). Moreover, as output in equilibrium is still only determined by aggregate demand, as prices are rigid, the equilibrium values of consumption and leisure are exactly the same as in the benchmark case. This explains why the price is pre-set at the same level as in equation (14). The expressions for the level and volatility effects are then unchanged, as well as the optimal monetary-policy rule. The only difference is that the real wage now fluctuates with the MRS ex-post. This has no real incidence in this pre-set price equilibrium, as wages are not allocative. Whether wages are rigid or flexible is then not key, both for the level and volatility effects. ${ }^{12}$

Rigid wages and flexible prices. We now consider sticky wages with flexible prices. The price rule (equation (3)) becomes:

$$
P=\frac{\varepsilon}{\varepsilon-1} \frac{W_{0}}{A}
$$

Wages are pre-set according to equation (5) where prices are now stochastic and fluctuate (only) through the influence of the technological shocks according to equation (21). Note that again equation (10) still holds. ${ }^{13}$ However, in contrast to the pre-set price case, consumption and leisure in equilibrium are no longer only determined by aggregate demand. Technological shocks now affect aggregate consumption, and not only labor. Nominal wage rigidity does not then lead to the same distortions as nominal price rigidity.

Plugging the equilibrium value of price into equation (10), and taking a second-order approximation around the deterministic path, the pre-set wage can be approximated as follows:

$$
\frac{1}{W_{0}} \approx \frac{\varepsilon}{\varepsilon-1}\left(1-\frac{1}{2}(1+\phi-\sigma) \operatorname{var}(M)-\frac{1}{2} \frac{(1-\sigma) \sigma}{\sigma+\phi} \operatorname{var}(A)\right)
$$

Taking a second-order approximation around the deterministic path of equation (21) implies that the average value of the general price index $P$ is:

$$
E\left[\frac{1}{P}\right] \approx 1-\frac{1}{2}(1+\phi-\sigma) \operatorname{var}(M)+\frac{1}{2}\left(\frac{\phi+\sigma^{2}}{\sigma+\phi}\right) \operatorname{var}(A)
$$

The average value of the price is not unambiguously above its deterministic counterpart. First, monetary shocks have the same ambiguous effect as in a pre-set price economy since money supply has exactly the same effect on real aggregates in the two economies. Second, the volatility of the technological shocks now reduces average prices. Following a technological shock, fluctuations in real balances reduce the risk associated with the fluctuations in the efficiency gap. The volatility of technological shocks then reduces the level effect in the welfare cost of fluctuations. This can be checked by deriving the approximate value of the welfare cost in the flexible-price

\footnotetext{
${ }^{12}$ This conclusion should be generalized in a dynamic framework. This is left for further research.

${ }^{13}$ The derivation of equation (10) is straightforward from the replacement of the price in equation (5) by equation (21).
} 
fixed-wage case, using equation (22) and a modified version of equation (13) where $P_{0}$ has been replaced by $P$, as prices are now stochastic:

$$
\begin{aligned}
E\left(\frac{\Delta}{U_{1}(\bar{C}) \bar{C}}\right) \approx & \underbrace{-\frac{\Phi}{2}\left[(2+\phi-\sigma) \operatorname{var}(M)-\frac{1+\sigma^{2}}{\sigma+\phi} \operatorname{var}(A)\right]}_{\text {Level Effect }} \\
& \underbrace{-\frac{1}{2}[(\phi+\sigma)-\Phi(1+\phi)]\left(\operatorname{var}(M)+\left(\frac{1-\sigma}{\sigma+\phi}\right)^{2} \operatorname{var}(A)\right)}_{\text {Volatility Effect }}
\end{aligned}
$$

As noted above, the level effect does not necessarily increase business-cycle costs when prices are flexible. Price flexibility reduces the level effect relative to the fixed-price case. The volatility effect also changes with flexible prices, and is reduced in size as we are now closer to the flexible price and wage allocation. Overall, for any parameter values, the relative importance of the level effect and the efficiency costs of business cycles fall (Table 2). On the other hand, laborsupply elasticity and the structural efficiency gap are still positively correlated with the relative importance of the level effect $(\gamma)$ and efficiency costs.

Table 2: Sensitivity Analysis (Flexible prices-Rigid wages)

\begin{tabular}{ccc|cc|cc}
\hline \hline & \multicolumn{4}{c}{$\phi=1$} & \multicolumn{2}{c}{$\phi=5$} \\
$\Phi$ & Welf. cost & $\gamma$ & Welf. cost & $\gamma$ & Welf. cost \\
$\Phi=0.5$ & 0.06 & 0.0083 & 0.71 & 0.0301 & 0.84 & 0.0556 \\
$\Phi=0.6$ & 0.08 & 0.0074 & 1.02 & 0.0296 & 1.24 & 0.0552 \\
$\Phi=0.7$ & 0.12 & 0.0064 & 1.51 & 0.0291 & 1.87 & 0.0548 \\
\hline \hline
\end{tabular}

Overall, this robustness analysis reveals that price rigidity is crucial for the analysis of the level effect. When prices are flexible, aggregate fluctuations in consumption and labor may reduce the risk associated with movements in the efficiency gap. This diminishes the importance of the level effect and thus the efficiency costs of business cycles. Note that this fall in size is exacerbated by a reduced volatility effect in this case.

On the other hand, it is straightforward to show that the monetary policy rule $M=A^{\frac{1-\sigma}{\sigma+\phi}}$ leads to the flexible-price economy allocation. ${ }^{14}$ When the wealth effect dominates the substitution effect in labor supply, i.e. $\sigma>1$, monetary policy should be counter-cyclical, in order to dampen the consumption response; the opposite holds for $\sigma<1$. When wealth and substitution effects cancel each other out in labor supply $(\sigma=1)$, there are no longer any gap fluctuations, even without policy intervention.

\footnotetext{
${ }^{14}$ This monetary-policy rule has to take price flexibility into account after a technology shock: $M=\frac{\epsilon-1}{\epsilon} \frac{W_{0}}{A} \bar{C}$. This implies that the pre-set wage is $W_{0}=\frac{\epsilon-1}{\epsilon}$
} 


\section{Conclusion}

This paper has shown that the costs of business cycles generated by nominal rigidities may be higher than previously documented in Gali et al. (2007). Price-setting behavior leads to lower average consumption and labor, relative to their flexible-price counterparts. For realistic calibration of the markups, this level effect can represent twice the efficiency costs of business cycles. Furthermore, taking this level effect into account affects the impact of some important parameters. It can in particular make a more distorted steady-state economy more vulnerable to business cycles; moreover, whereas consumer risk aversion increases the welfare costs of volatility in the efficiency gap, it dampens the impact of this volatility on mean consumption. Moreover, the level effect reinforces the impact of low labor-supply elasticity on business-cycle costs.

The paper reveals in a transparent way how a distorted economy can change the implications of aggregate fluctuations, and questions the traditional approach that consists in considering optimal policies when the structural distortions have been totally eliminated by appropriate subsidies. In this case, it is consistent to put the level effect to one side as its implied cost is zero. However, this is an artificial case and potentially misleading: monetary policy should be analyzed in a distorted steady-state economy in order to properly evaluate the gains from stabilizing fluctuations. Our paper makes this point explicit and suggests that it should be followed up in the more general frameworks found in, for example, Khan et al. (2003), Benigno and Woodford (2005) and Schmitt-Grohé and Uribe (2007). 


\section{References}

Attanasio, O., J. Banks, C. Meghir and G. Weber (1999), 'Humps and bumps in life-time consumption', Journal of Business and Economics Statistics 17.

Ball, L. and D. Romer (1989), 'Are prices too sticky?', Quarterly Journal of Economics 104, 50724.

Benigno, P. and M. Woodford (2005), 'Inflation stabilization and welfare: The case of a distorted steady state', Journal of the European Economic Association 3, 1-52.

Fischer, S. (1977), 'Long-term contracts, rational expectations, and the optimal money supply rule', Journal of Political Economy 85, 191-205.

Gali, J. (2008), Monetary Policy, Inflation and the Business Cycle: An Introduction to the New Keynesian Framework, Princeton University Press.

Gali, J., M. Gertler and D. Lopez-Salido (2007), 'Markups, gaps, and the welfare costs of business fluctuations', The Review of Economics and Statistics 89, 44-59.

Khan, A., King R. and A. Wolman (2003), 'Optimal monetary policy', Review of Economic Studies 70, 825-860.

Mankiw, G. (1985), 'Small menu costs and large business cycles', Quarterly Journal of Economics 100, 529-37.

Phelps, E. and J. Taylor (1977), 'Stabilizing powers of monetary policy under rational expectations', Journal of Political Economy 85, 163-190.

Schmitt-Grohé, S. and M. Uribe (2007), 'Optimal, simple, and implementable monetary and fiscal rules', Journal of Monetary Economics 54, 1702-1725.

Sutherland, A. (2002), A simple second-order solution method for dynamic general equilibrium models. CEPR discussion paper no. 3554, July.

Woodford, M. (2003), Interest and Prices: Foundations of a Theory of Monetary Policy, Princeton University Press.

\section{A The Ramsey problem}

The objective of state-contingent monetary policy is to maximize expected social welfare subject to the implementability conditions formed by the price-setting rules summarized in equation (10) 
and the production technology implying $L(s)=C(s) / A(s)$ :

$$
\begin{array}{ll} 
& \max _{C(s)} \sum_{s} \pi(s)\{U(C(s), C(s) / A(s))\} \\
\text { s.t. } & 0=\sum_{s} \pi(s)\left[(1-\Phi) U_{1}(C(s)) C(s)-U_{2}(C(s) / A(s))(C(s) / A(s))\right] \quad \forall s
\end{array}
$$

The Lagrangian of this problem is then

$$
\mathcal{L}=\sum_{s} \pi(s)\left\{U\left(C(s), \frac{C(s)}{A(s)}\right)+\lambda \sum_{s} \pi(s)\left[(1-\Phi) U_{1}(C(s)) C(s)-U_{2}\left(\frac{C(s)}{A(s)}\right)\left(\frac{C(s)}{A(s)}\right)\right]\right\}
$$

The associated first-order condition is:

$$
\begin{gathered}
\pi(s)\left(U_{1}(C(s))-\frac{1}{A(s)} U_{2}(C(s) / A(s))\right) \\
+\sum_{s^{\prime} \neq s} \pi\left(s^{\prime}\right) \lambda \pi(s)\left[(1-\Phi)\left(U_{11}(C(s)) C(s)+U_{1}(C(s))\right)-\frac{1}{A(s)}\left(U_{22}\left(\frac{C(s)}{A(s)}\right)\left(\frac{C(s)}{A(s)}\right)+U_{2}\left(\frac{C(s)}{A(s)}\right)\right)\right] \\
+\lambda \pi(s)^{2}\left[(1-\Phi)\left(U_{11}(C(s)) C(s)+U_{1}(C(s))\right)-\frac{1}{A(s)}\left(U_{22}\left(\frac{C(s)}{A(s)}\right)\left(\frac{C(s)}{A(s)}\right)+U_{2}\left(\frac{C(s)}{A(s)}\right)\right)\right]=0
\end{gathered}
$$

implying that:

$$
\begin{array}{r}
\left(U_{1}(C(s))-\frac{1}{A(s)} U_{2}(C(s) / A(s))\right) \\
+\lambda\left[(1-\Phi)\left(U_{11}(C(s)) C(s)+U_{1}(C(s))\right)-\frac{1}{A(s)}\left(U_{22}\left(\frac{C(s)}{A(s)}\right)\left(\frac{C(s)}{A(s)}\right)+U_{2}\left(\frac{C(s)}{A(s)}\right)\right)\right]=0
\end{array}
$$

Given the form of the utility function, implying that:

$$
\begin{aligned}
U_{11}(C(s)) C(s)+U_{1}(C(s)) & =U_{1}(C(s))(1-\sigma) \\
U_{22}(C(s) / A(s))(C(s) / A(s))+U_{2}(C(s) / A(s)) & =U_{2}(C(s) / A(s))(1+\phi)
\end{aligned}
$$

we deduce from the FOC that:

$U_{1}(C(s))-\frac{1}{A(s)} U_{2}(C(s) / A(s))+\lambda\left[(1-\Phi) U_{1}(C(s))(1-\sigma)-\frac{1}{A(s)} U_{2}(C(s) / A(s))(1+\phi)\right]=0$

Using the definition of $G A P(s)$, we then obtain:

$$
1-G A P(s)+\lambda[(1-\Phi)(1-\sigma)-(1+\phi) G A P(s)]=0
$$

Taking expectations over this last equation, we obtain the solution for $\lambda$, using the implementability constraint:

$$
\lambda=\Phi \frac{\sum_{s} \pi(s) U_{1}(C(s)) C(s)(1-G A P(s))}{\sum_{s} \pi(s) U_{1}(C(s)) C(s)[\phi G A P(s)+\sigma(1-\Phi)]}
$$

We then deduce that:

$1-G A P(s)+\Phi\left(\frac{\sum_{s} \pi(s) U_{1}(C(s)) C(s)(1-G A P(s))}{\sum_{s} \pi(s) U_{1}(C(s)) C(s)[\phi G A P(s)+\sigma(1-\Phi)]}\right)[(1-\Phi)(1-\sigma)-(1+\phi) G A P(s)]=0$

The flexible-price solution $G A P(s)=1-\Phi, \forall s$, satisfies this equation, showing that the flexibleprice allocation is optimal. 